\section{JURNAL ABDIMAS

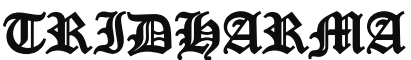

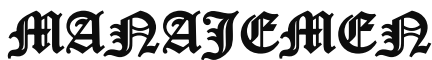

P-ISSN 2615-6849, E-ISSN 2622-3686

Jurnal ABDIMAS Vol.1,No.3,September2020,Hal(103-110)

@ Prodi Manajemen Fakultas Ekonomi Universitas Pamulang

Email: abdimasjurnal.unpam@gmail.com Telp: (021) 741-2566

\title{
PENYULUHAN AQUAPONIK DALAM MASA PANDEMI COVID-19 DI RT. 003, RW. O06 DESA KABASIRAN
}

\author{
Cornelia Dumarya Manik, Aidil Amin Effendy, Rian Sri Rahayu, \\ Iis Noviyanti, Syarifah Ida Farida
}

Dosen Manajemen Universitas Pamulang

Email dosen00720@unpam.ac.id,dosen00967@unpam.ac.id, dosen00969@unpam.ac.id, dosen01107@unpam.ac.id, dosen01477@unpam.ac.id

\begin{abstract}
ABSTRAK
Tujuan dari pelaksanaan Pengabdian Kepada Masyarakat yang berjudul "Penyuluhan Aquaponik Dalam Masa Pandemi Covid-19 Pada RT. 003, RW. 006 Desa Kabasiran" adalah sebagai upaya pemenuhan kewajiban Tri Dharma Perguruan Tinggi. Pengabdian kepada masyarakat ini bertujuan untuk membantu masyarakat khususnya pada masyarakat di desa Kabasiran dalam berwirausaha saat masa Pandemi Covid-19 yaitu mengenai sistem budidaya Aquaponik. Pengabdian Kepada Masyarakat dilakukan di RT. 003, RW. 006 Desa Kabasiran Bogor, pada tanggal 26-28 Juni 2020.

Berdasarkan hal di atas, kegiatan pengabdian kepada masyarakat dengan memberikan informasi dan atau tambahan pengetahuan mengenai pengembangan kemampuan masyarakat dalam budidaya Aquaponik yaitu cara menanam tanaman dan memelihara ikan dalam satu wadah, sebagai wujud eksistensi Perguruan Tinggi yang bertujuan untuk memberikan konstribusi besar kepada pengembangan dan penerapan ilmu kepada masyarakat.

Metode yang digunakan pada Pengabdian Kepada Masyarakat ini berupa ekspositori yaitu penyampaian materi secara verbal dan inquiry yaitu pembelajaran yang menekankan pada proses berpikir kreatif kritis dan analitis terkait materi dan praktik budidaya Aquaponik, diharapkan masyarakat dapat mempraktekkan budidaya Aquaponik ini sebagai salah satu alternatif usaha di tengah pandemi Covid-19.

Hasil Pengabdian Kepada Masyarakat yang diperoleh adalah masyarakat dapat mengetahui dan mempraktekkan sistem budidaya Aquaponik dalam sebuah wadah, namun masyarakat masih perlu mendalami kembali sistem budidaya Aquaponik ini agar hasilnya dapat lebih maksimal.
\end{abstract}

Kata Kunci : Aquaponik, Masa Pandemi Covid-19, Desa Kabasiran

\begin{abstract}
The purpose of implementing Community Service entitled "Aquaponic Counseling During the Covid-19 Pandemic at RT. 003, RW. 006 Kabasiran Village "is an effort to fulfill the obligations of the Tri Dharma of Higher Education. This community service aims to help the community, especially the people in Kabasiran village, in entrepreneurship during the Covid-19 Pandemic,
\end{abstract}




\section{JURNAL ABDIMAS

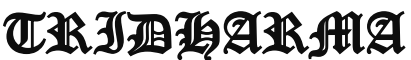

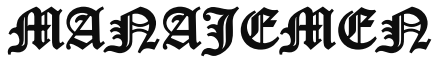

P-ISSN 2615-6849, E-ISSN 2622-3686

Jurnal ABDIMAS Vol.1,No.3,September2020,Hal(103-110)

@ Prodi Manajemen Fakultas Ekonomi Universitas Pamulang

Email: abdimasjurnal.unpam@gmail.com Telp: (021) 741-2566

namely regarding the Aquaponic cultivation system. Community Service is carried out at RT. 003, RW. 006 Desa Kabasiran Bogor, on 26-28 June 2020.

Based on the above, community service activities by providing information and / or additional knowledge regarding the development of community capacity in aquaponic cultivation, namely how to grow plants and raise fish in one container, as a form of the existence of a higher education that aims to make a major contribution to the development and application of science to society.

The method used in this Community Service is in the form of expository, namely the delivery of material verbally and inquiry, namely learning that emphasizes critical and analytical creative thinking processes related to material and aquaponic cultivation practices, it is hoped that the community can practice this Aquaponic cultivation as an alternative business in the midst of a pandemic. Covid-19.

The results of community service obtained are that people can know and practice the Aquaponic cultivation system in a container, but people still need to re-examine this Aquaponic cultivation system so that the results can be maximized

\section{Keywords: Aquaponiks, Covid-19 Pandemic Period, Kabasiran Village}

\section{PENDAHULUAN}

Jawa barat merupakan provinsi yang semakin naik kasus pandemi ini, sehingga dikeluarkannya peraturan daerah mengenai pembatasan sosial berskala besar. Ada pun dampak untuk warga yang kesehariannya sebagai guru ngaji honorer, pedagang, pelayanan yang penghasilannya didapatkan dengan cara bertemu langsung dengan para konsumen atau kliennya.

Dari hasil survey dan wawancara melalui rumah shodaqoh bahwa permasalahan yang ada sekarang ini dan masih berlanjut salah satunya yaitu guru ngaji yang didaerah perkampungan parung panjang tidak mendapatkan penghasilan, dikarenakan tidak bisa keluar rumah untuk memberikan ilmunya secara langsung kepada murid-muridnya.

Kemendikbud menyarankan untuk memberikan pembelajaran secara online/daring, hal ini tidak bisa dilakukan oleh guru ngaji dan murid yang tidak memiliki alat komunikasi yang bisa mendukung pembejalaran tersebut. Selain itu, mereka juga tidak memiliki kuota yang besar untuk melakukan media pembelajaran melalui zoom atau webex yang dilakukan oleh sekolah-sekolah swasta lainnya.

Salah satu solusi yang diberikan terhadap permasalahan mitra yang merupakan guru ngaji di daerah parung panjang bogor. Dengan adanya pandemi covid-19 mereka tidak mendapatkan penghasilan dikarenakan semuanya tidak diizinkan untuk keluar rumah. Sehingga tidak memungkinkan untuk pembelajaran secara daring. Kami selaku dosen manajemen memiliki target dalam kegiatan ini untuk membantu kemitraan rumah shodaqoh meningkatkan kegiatan UMKM di daerahnya, sehingga mereka bisa mendapatkan penghasilan dan mencukupi kebutuhannya akan keluarganya dalam sehari-hari. 


\section{JURNAL ABDIMAS

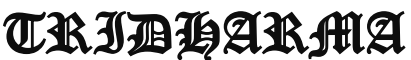

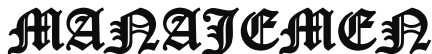

P-ISSN 2615-6849, E-ISSN 2622-3686

Jurnal ABDIMAS Vol.1,No.3,September2020,Hal(103-110)

@ Prodi Manajemen Fakultas Ekonomi Universitas Pamulang

Email: abdimasjurnal.unpam@gmail.com Telp: (021) 741-2566
Oleh karena itu dosen universitas pamulang khususnya program studi manajemen bekerjasama dengan rumah shodaqoh memberikan penyuluhan tentang Aquaponik dan juga bantuan berupa pangan (sembako) untuk para guru ngaji tersebut. Selain itu, kegiatan ini membantu mereka untuk melakukan kegiatan kemitraan melalui pendistribusian sembako kepada para guru ngaji yang tidak mendapatkan penghasilan tersebut.

Regulasi terhadap isu lingkungan pun diberlakukan oleh beberapa negara sebagai pembelajaran dan pembiasaan terhadap warga negaranya untuk lebih peduli terhadap lingkungannya sebagai contoh mengurangi konsumsi kantong plastik dengan membeli kantong plastik berbayar. Sistem ini memakasa kita (manusia) untuk lebih bijak lagi memilih kantong belanja dengan harapan dapat mengurangi penggunaan kantong plastik.

Tidak hanya dalam bentuk regulasi, kampanye terhadap kerusakan lingkungan juga sering digaungkan oleh sekumpulan orang yang peduli terhadap lingkungan baik itu dalam lingkungan rumah tangga, sekolah, perkantoran ataupun universitas. Merujuk dari undang-undang dan peraturan pemerintah tersebut, beberapa pemimpin daerah yang meningkat penyebaran covid-19 mengajukan psbb ke kementerian kesehatan. Semakin banyak pengalaman yang telah didapatkan dalam dunia kerja dan dalam kehidupan, semakin lengkap jalur karir unik yang akan dimiliki seseorang.

Seluruh pengalaman kehidupan baik itu merupakan pekerjaan yang dibayar, kegiatan pengaturan rumah tangga sekalipun dapat digunakan sebagai bukti bahwa seseorang pernah bertanggung jawab atas pekerjaannya. Hal ini dapat menjadi salah satu motivasi masyarakat untuk menerapkan bisnis mandiri dan kreatif (ridwan, itbcentercareer wordpress.com 09 desember 2014) di lingkungan rumah agar dapat menjaga keseimbangan lingkungan kita dapat melakukan langkah seperti: mengurangi membeli produk ukuran besar dan tidak terlalu penting menjadi membeli produk yang dapat diisi ulang.

Hal kedua kita dapat memilah sampah kemasan produk yang ada 3 (tiga) kategorinya: organik, anorganik dan logam atau kaca. Kemudian kita dapat memanfaatkan sampah organik menjadi pupuk kompos, dan sampah anorganik menjadi daur ulang (recycle) dan digunakan kembali (reuse). sebenarnya, sistem perkebunan semacam ini sudah lama diadopsi sejumlah negara dengan sumber daya lahan terbatas. Ia semacam teknologi budidaya terpadu antara ikan dan tanaman.

Teknologi terapan ini irit lahan dan air, hingga mudah diterapkan di perkotaan dengan lahan sempit. kami ingin membantu memberikan pelatihan kewirausahan kepada masyarakat sekitar Desa Kabasiran sehingga mereka bisa meningkatkan penghasilan di masa Pandemi ini selain itu bermanfaat untuk keluarga dan masyarakat. Masalah utama yang dihadapi oleh RUMAH SODAQOH adalah pemasaran (Hafsah, 2004; Kuncoro, 2008); Kurniawan, 2009; Supardi, 20009).

Aquaponik biayanya relatif murah, dengan memanfaatkan waktu, dan peralatan seperti ember ukuran besar, ikan, pelet dan bibit sayur ditempatkan dalam ditempat yang sama akan menghemat biaya dan waktu. Untuk itu, 


\section{JURNAL ABDIMAS

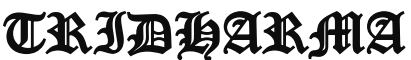

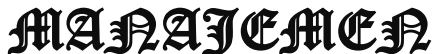

P-ISSN 2615-6849, E-ISSN 2622-3686

Jurnal ABDIMAS Vol.1,No.3,September2020,Hal(103-110)

@ Prodi Manajemen Fakultas Ekonomi Universitas Pamulang

Email: abdimasjurnal.unpam@gmail.com Telp: (021) 741-2566 kami Dosen Universitas Pamulang dan mahasiswa mengadakan Pengabdian Kepada Masyarakat (PKM) bekerjasama dengan Lembaga Pemberdayaan Masyarakat (LPM) Desa Kabasiran untuk memberikan pelatihan kepada warga dengan judul "Penyuluhan Aquaponik Dalam Masa Pandemi Covid-19 Pada RT. 003, RW. 006 Desa Kabasiran"

\section{RUMUSAN MASALAH}

Berdasarkan latar belakang diatas dapat dirumusan permasalah dalam pelaksanaan pengabdian masyarakat bagi masyarakat desa Kabasiran:

1. Bagaimana memberikan pemahaman teknik kepada para peserta membuat Aquaponik dengan mudah dan terjangkau?

2. Bagaimana memberikan pengetahuan pemasaran kepada para peserta membuat strategi mendapatkan penghasilan dari Aquaponik?

3. Bagaimana memberikan pengarahan kepada peserta membuat kelompok UMKM khusus Aquaponik?

\section{TUJUAN PELAKSANAAN}

Tujuan pelaksanaan pengabdian msyarakat di masyarakat desa Kabasiran adalah:

1. Memberikan pemahaman teknik kepada para peserta membuat Aquaponik dengan mudah dan terjangkau

2. Memberikan pengetahuan pemasaran kepada para peserta membuat strategi mendapatkan penghasilan dari Aquaponik
3. Memberikan pengarahan kepada peserta membuat kelompok UMKM khusus Aquaponik

\section{TINJAUAN PUSTAKA}

\section{Aquaponik}

Aquaponik adalah system budidaya ikan (akuakultur )dan tanaman (hidroponik) bersama dalam sebuah ekosistem yang resirkulasi/saling menguntungkan yang menggunakan bakteri alami untuk mengubah kotoran \& sisa pakan ikan menjadi nutrisi tanaman. Dengan kata lain akuaponik adalah system dimana tanaman dan ikan bertumbuh bersama

Dengan menggabungkan kedua sistem tersebut, terjadi daur ulang sehingga limbah dari sistem akuakultur merupakan input sistem hidroponik. Dengan menggabungkan akuakultur menjadi akuaponik, limbah yang dibuang ke alam menjadi sangat minimal.Sehingga boleh dikatakan sistem akuaponik adalah sistem yang ramah lingkungan

\section{Penyuluhan}

Margono Slamet (2000) menegaskan bahwa inti dari kegiatan penyuluhan adalah untuk memberdayakan masyarakat. Memberdayakan berarti memberi daya kepada yang tidak berdaya dan atau mengem-bangkan daya yang sudah dimiliki menjadi sesuatu yang lebih ber-manfaat bagi masyarakat yang bersangkutan. Dalam konsep pemberdayaan tersebut, terkandung pema-haman bahwa pemberdayaan tersebut pengertian dapat mengambil keputusan (yang terbaik) bagi kesejahteraannya sendiri. 


\section{JURNAL ABDIMAS

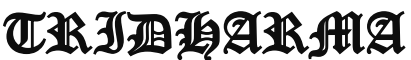

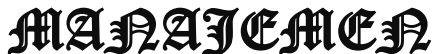

P-ISSN 2615-6849, E-ISSN 2622-3686

Jurnal ABDIMAS Vol.1,No.3,September2020,Hal(103-110)

@ Prodi Manajemen Fakultas Ekonomi Universitas Pamulang

Email: abdimasjurnal.unpam@gmail.com Telp: (021) 741-2566
Pemberdayaan

dimaksudkan untuk

masyarakat, memperkuat kemampuan (capacity strenghtening) masyarakat, agar mereka dapat berpar-tisipasi secara aktif dalam keseluruahn proses pembangunan, terutama pembangunan yang ditawarkan oleh penguasa dan atau pihak luar yang lain (penyuluh, LSM, dll) Dalam PKM (Pengabdian Kepada Masyarakat) Tujuan yang ingin diraih dalam membuat produk yang bermanfaat dan inovatif dengan tujuan utamanya meningkatkan kesejahteraan hidup bagi masyarakat.

\section{Kewirausahaan}

Adapun PKM ini berkolaburasi dengan Ilmu kewirausahaan adapun arti dari Kewirausahaan merupakan kecakapan hidup yang penting dimiliki oleh setiap orang. Kewirausahaan dapat dipelajari dan dikuasai. Orang yang memiliki semangat kewirausahaan disebut wirausaha atau lebih dikenal oleh masyarakat sebagai pengusaha. Selain itu Wirausaha akan muncul dan berkembang bila ada peluang dan tantangan dalam bidang ekonomi.

Dan

Kewirausahaan merupakan sumber daya ekonomi, selain modal, tenaga kerja dan tanah atau lahan. Selain itu Wirausahalah yang dapat mengupayakan agar modal, tenaga kerja, dan tanah dapat menghasilkan barang dan jasa yang dibutuhkan masyarakat, sehingga memperoleh keuntungan atas usahanya tersebut. Dalam konteks kewirausahaan, terdapat dua terminologi yang berbeda secara konsep namun memiliki kesamaan dalam praktik.

Kedua terminologi tersebut adalah enterpreneurship dan intrapreneurship. Enterprenuership dapat diartikan sebagai kemampuan mengelola usaha sendiri (menjadi bos/atasan untuk dirinya sendiri), sementara intrapreneurship diartikan sebagai kemampuan menerapkan konsep wirausaha dalam mengelola usaha milik orang lain (memiliki bos/atasan yang bukan dirinya sendiri).

\section{METODE PELAKSANAAN}

Metode pelaksanaan pengabdian ini dilakukan dalam beberapa kegiatan yaitu tahap survey adalah sosialisasi dilakukan dengan mempersiapkan berbagai hal yang terkait pada saat kegiatan pengabdian yang akan dilakukan yaitu dalam Aidil Amin Effendy,dkk., (2020): persiapan materi yang akan diberikan, penyusunan jadwal penyuluhan, pembagian tugas tim pengabdian dan survey ke lokasi pengabdian. Tahap sosialisasi yaitu sebelum kegiatan pengabdian dilakukan terlebih dahulu tahap sosialisasi yaitu bersilaturahim dengan kepala desa Kabasiran untuk menyampaikan maksud dan tujuan pengabdian ini. Pada tahap ini juga dilakukan perjanjian kerjasama dan menentukan jadwal kegiatan pengabdian. Kemudian tahap terakhir yaitu tahap penyuluhan (pelatihan) yaitu Tim pengabdian kepada masyarakat adalah dosen dan mahasiswa Fakultas Ekonomi jurusan manajemen Universitas Pamulang. Tahap ini Tim pengabdian memberikan materi kegiatan pengabdian kepada masyarakat yang bertujuan untuk dapat meningkatkan pengetahuanya mengenai sistem budidaya Aquaponik. Adapun Prof. Dr. S. Nasution (2015:26) berpendapat mengenai "Ciriciri Belajar yang ditinjau berdasarkan sumber yaitu diantaranya 


\section{JURNAL ABDIMAS

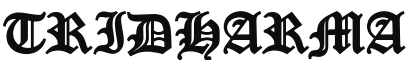

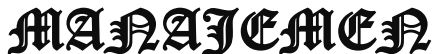

P-ISSN 2615-6849, E-ISSN 2622-3686

Jurnal ABDIMAS Vol.1,No.3,September2020,Hal(103-110)

@Prodi Manajemen Fakultas Ekonomi Universitas Pamulang

Email: abdimasjurnal.unpam@gmail.com Telp: (021) 741-2566 memanfaatkan sepenuhnya segala sumber informasi sebagai sumber bagi pelajaran termasuk alat-alat audiovisual dan memberi kesempatan untuk merencanakan kegiatan belajar dengan mempertimbangkan sumber-sumber yang tersedia." Dalam pemberian materi PKM oleh dosen-dosen menggunakan alat bantu berupa infocus agar guru-guru sebagai audience lebih fokus dalam mengikuti penyuluhan. Setelah pemberian materi, Tim PKM Unpam mengajarkan simulasi mengenai sistem budidaya Aquaponik kepada masyarakat desa Kabasiran. Kemudian diakhiri dengan diskusi dan tanya jawab mengenai materi dan simulasi yang disampaikan. Kegiatan pengabdian ini diadakan terhadap masyarakat desa Kabasiran selama 3 hari yaitu pada hari Jum'at-Minggu, tanggal 26-28 Juni 2020.

\section{HASIL DAN PEMBAHASAN}

Pengabdian kepada Masyarakat (PKM) Universitas Pamulang yang dilakukan oleh dosen-dosen program studi Manajemen telah berjalan dengan lancar dan mendapat sambutan hangat dari peserta PKM, terlihat dari antusiasnya peserta PKM dalam mengikuti pengabdian ini.

Dosen-dosen Unpam sebagai TIM PKM (Pengabdian kepada Masyarakat) memberikan sembako sebagai bantuan saat masa Pandemi Covid-19 ini dan juga pemberian materi pelatihan dan simulasi mengenai "Penyuluhan Aquaponik Dalam Masa Pandemi Covid-19 Pada RT. 003, RW. 006 Desa Kabasiran" dengan tujuan agar masyarakat dapat mengetahui dan mempraktekkan sistem budidaya Aquaponik dalam sebuah wadah, namun masyarakat masih perlu mendalami kembali sistem budidaya Aquaponik ini agar hasilnya dapat lebih maksimal.

Setelah pemberian sembako, Tim PKM memberikan materi mengenai "Penyuluhan Aquaponik Dalam Masa Pandemi Covid-19 Pada RT. 003, RW. 006 Desa Kabasiran". Setelah pemberian materi, Tim PKM memberikan simulasi mengenai Budidaya Aquaponik pada masyarakat Desa Kabasiran. Teori dan Simulasi diberikan agar masyarakat dapat mendalami secara utuh mengenai sistem budidaya Aquaponik.

Hasil dari Pelaksanaan kegiatan PKM oleh dosen-dosen Fakultas Ekonomi Universitas Pamulang dapat membuahkan hasil yang positif terlihat dari antusiasnya dan bersemangatnya peserta PKM yang terdiri guru-guru ngaji dan masyarakat Desa Kabasiran dalam mengikuti pemberian materi, tanya jawab dan kuis.

\section{KESIMPULAN DAN SARAN Kesimpulan}

Dengan adanya penyuluhan yang dilakukan Tim PKM dosen dan mahasiswa Unpam, masyarakat desa Kabasiran sudah dapat mengetahui pengetahuan yang disampaikan oleh Tim PKM dosen Unpam dan memiliki kemampuan untuk dapat berwirausaha dalam memanfaatkan budidaya Aquaponik.

Peserta PKM yaitu guru-guru ngaji dan masyarakat Desa Kabasiran masih belum dapat membuat budidaya Aquaponiknya secara maksimal, maka perlu melatih dan mendalami kembali agar lebih baik dalam membuat budidaya Aquaponik.

\section{Saran}




\section{JURNAL ABDIMAS

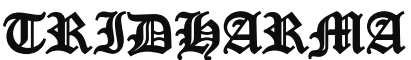

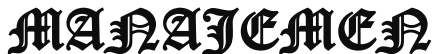

P-ISSN 2615-6849, E-ISSN 2622-3686

Jurnal ABDIMAS Vol.1,No.3,September2020,Hal(103-110)

@ Prodi Manajemen Fakultas Ekonomi Universitas Pamulang

Email: abdimasjurnal.unpam@ gmail.com Telp: (021) 741-2566
Perlu secara reguler diberikan pelatihan untuk meningkatkan pengetahuan dan kapabilitas guru-guru ngaji dan masyarakat Desa Kabasiran untuk membuat budidaya Aquaponiknya secara maksimal dan alternatif peluang usaha di masa Pandemi Covid-19

\section{DAFTAR PUSTAKA.}

Effendy, A. A., Mas'adi, M., Wicaksono, W., Nurhadi, A., \& Murtiyoko, H. (2020). Mewujudkan Generasi Muda Yang Unggul Di Era Globalisasi Dengan Berbekal Ilmu Wirausaha Yang Kreatif, Inovatif Dan Diferensiatif Pada Remaja Masjid Al Hikmah Reni Jaya Pamulang Tangerang Selatan. Jurnal Pengabdian Dharma Laksana, 3(1), 8-15.

Effendy, A. A., Murtiyoko, H., \& Wicaksono, W. (2019). Pemberian Motivasi Dalam Membangun Genenerasi Muda Yang Berkompeten Dan Religius Pada Madrasah Aliyah Ummul Qura Pondok Cabe, Pamulang Tangerang Selatan. Jurnal Pengabdian Dharma Laksana, 2(1), 1-5

Effendy, A. A., Sudarso, A. P., Nurhadi, A., Arifianto, C. F., \& Kartono, K. (2020). Peningkatan Profesionalisme Guru Dan Pengembangan SDM Dalam Menghadapi Era Revolusi Industri 4.0 Pada Guru Smk Mulia Buana Parung Panjang Bogor. Abdi Laksana, 1(2).

Farida, S. I., Iqbal, M., \& Kurniasih, A. (2016). Pengaruh Kepercayaan Dan Komitmen Organisasi Terhadap Motivasi Kerja Serta Implikasinya Pada Kepuasan Kerja. Jurnal Kependidikan: Penelitian Inovasi Pembelajaran, 46(1), 121-134.
Farida, S. I. (2018). Anggaran responsif gender sebagai suatu instrumen negara untuk pemenuhan hak perempuan di Indonesia. JIMF (Jurnal Ilmiah Manajemen Forkamma), 1(2).

Farida, S. I., Prasetiyani, D., Safiih, A. R., Prasada, D., \& Ismanto, B. (2020). Pelatihan SDM: Usaha Konvensional menjadi Usaha Digital. Jurnal Abdi Masyarakat Humanis, 1(2).

Farida, S. I., \& Anjani, S. R. (2019). Menumbuhkan Jiwa Kepemimpinan Pada Mahasiswa di Lingkungan Universitas

Pamulang. INOVASI, 6(2), 19-20.

Farida, S. I., \& Khair, O. I. (2019). Leadership sebagai Dasar Kecerdasan Intelektual Mahasiswa Program Studi Manajemen di Universitas Pamulang. JIMF (Jurnal Ilmiah

Manajemen Forkamma), 3(1).

Jauhari, J. (2010). Upaya Pengembangan Usaha Kecil dan Menengah (RUMAH SODAQOH) dengan Memanfaatkan ECommerce. Jurnal Sistem Informasi (JSI), Vol. 2., No. 1, 159168.

Nasution, Prof. Dr. S., (2015). "Berbagai Pendekatan dalam Proses Belajar dan Mengajar", PT Bumi Aksara, Jakarta

Pasaribu, V. L. D., Susanti, F., \& Hartuti, E. T. K. (2019). Memotivasi Siswa dan Siswi SMK Letris Indonesia di Dalam Menentukan Pilihan Untuk Melanjutkan Pendidikan Atau Bekerja Setelah Lulus Sekolah. Jurnal Pengabdian Dharma Laksana, 1(2), 161-172.

Pasaribu, V. L. D., Agrasadya, A., Shabrina, N., \& Krisnaldy, K. (2020). MENJADI ENTERPRENEUR MUDA YANG MEMILIKI JIWA LEADERSHIP UNTUK 


\section{JURNAL ABDIMAS

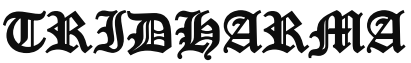 AlA:}

P-ISSN 2615-6849, E-ISSN 2622-3686

Jurnal ABDIMAS Vol.1,No.3,September2020,Hal(103-110)

@Prodi Manajemen Fakultas Ekonomi Universitas Pamulang

Email: abdimasjurnal.unpam@gmail.com Telp: (021) 741-2566
MENGHADAPI MASA DEPAN. Abdi

Laksana, 1(1).

Pasaribu, V. L. D., Elburdah, R. P., Sudarso, E., \& Fauziah, G. (2020). PENGGUNAAN MANAJEMEN WAKTU TERHADAP PENINGKATAN PRESTASI BELAJAR DI SMP ARAISIYAH. Jurnal ABDIMAS Tri Dharma Manajemen, 1(1).

Pasaribu, V. L. D., Sulaiman, S., Sutiman, S., Thaharudin, T., \& Purnomo, B. Y. (2020). PENGENALAN LETAK POSYANDU TERDEKAT DIKELURAHAN PISANGAN DENGAN MANAJEMEN PEMASARAN REVOLUSI 4.0 UNTUK MENINGKATKAN PENGETAHUAN MASYARAKAT LETAK DAN FUNGSI POSYANDU TERDEKAT PADA KELURAHAN PISANGAN. DEDIKASI PKM, 1(1), 105-110.

Pasaribu, V. L. D., Oktrima, B., Prabowo, B., Arianto, N., \& Haryoko, U. B. (2020) PROGAM PENDAMPINGAN DAN PENYELENGGARAAN

PENDIDIKAN ANAK PADA USIA DINI TERHADAP PRESTASI BELAJAR DILINGKUNGAN RT 020 RW 009. KEL GIRI PENI. KEC WATES. YOGYAKARTA. JURNAL LOKABMAS KREATIF, 1(1), 71-75

Yuangga, K. D., \& Manik, C. D. (2018). Menumbuhkan Motivasi Pendidikan Dan Wirausaha Yang Ramah Lingkungan Untuk Meningkatkan Kesejahteraan Ekonomi Keluarga. Jurnal Pengabdian Dharma Laksana, 1(1), 31-40.

\section{DOKUMENTASIKEGIATAN}

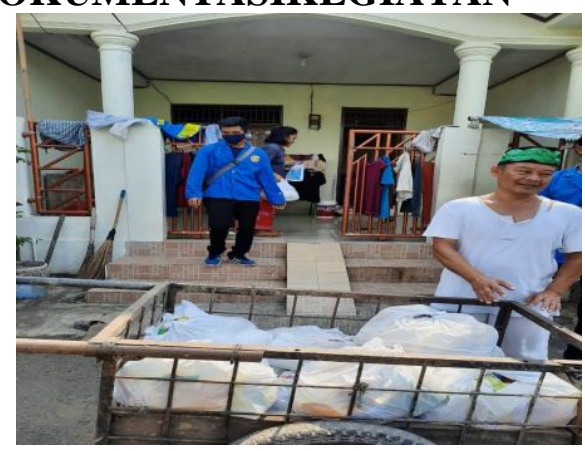

Gambar 1. Pemberian sembako oleh Tim PKM

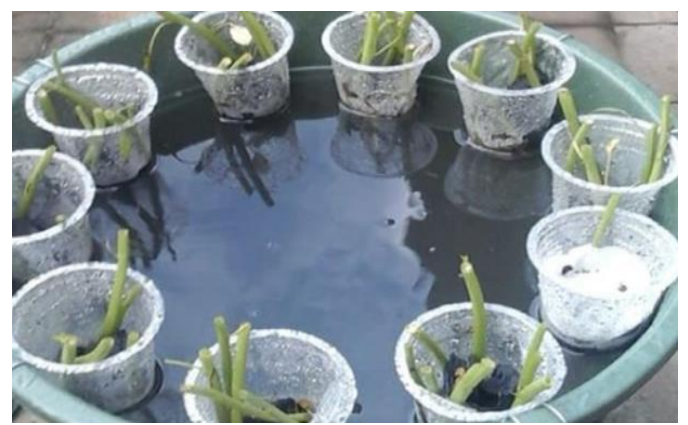

Gambar 2. Hasil Simulasi Sistem Budidaya Aquaponik

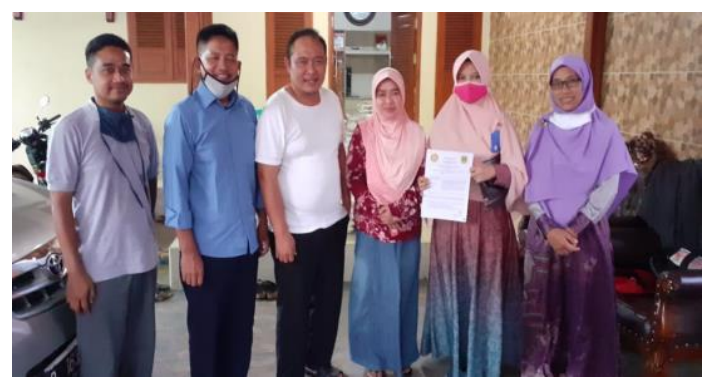

Gambar 3. Tim PKM dengan Kepala Desa Kabasiran Bapak H. Jajang Atmajaya

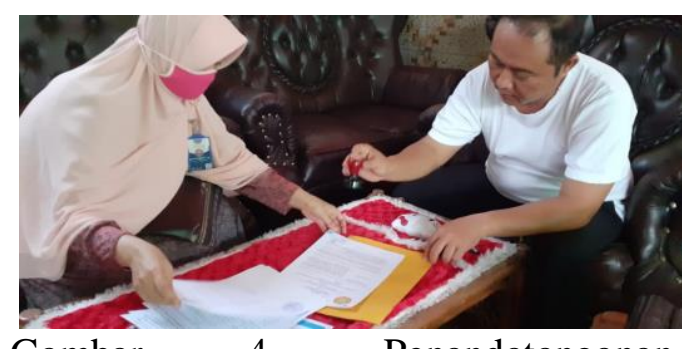

Gambar 4. Penandatanganan Implementation Arrangement oleh Kepala Desa Kabasiran Bapak $\mathrm{H}$. Jajang Atmajaya 